\title{
Effects of traffic signal coordination on noise and air pollutant emissions
}

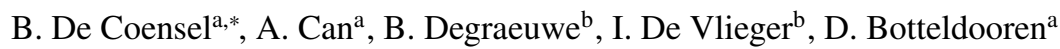 \\ ${ }^{a}$ Ghent University, Department of Information Technology, Acoustics research group, St.-Pietersnieuwstraat 41, B-9000 Ghent, Belgium \\ ${ }^{b}$ Flemish Institute for Technological Research (VITO), Boeretang, B-2400 Mol, Belgium
}

\begin{abstract}
Traffic management solutions are increasingly called for to address problems of transport and mobility. In particular, coordinated traffic lights that create green waves along major arterials are an increasingly used strategy to reduce travel times. Although it is usually assumed that an improved traffic flow will result in lower vehicle emissions, little scientific research has been spent on the effects of synchronized traffic lights on emissions. Moreover, because changes in traffic flow do not necessarily influence travel times, noise and air quality in the same way, there is a clear need for a combined approach. This paper reports on a computational study in which a microscopic traffic simulation model (Paramics) is combined with submodels for the emission of noise (Imagine) and air pollutants (VERSIT+). Through the simulation of a range of scenarios, the model is used to investigate the influence of traffic intensity, signal coordination schemes and signal parameters on the noise, carbon dioxide, nitrogen oxides and particulate matter emissions along an arterial road equiped with a series of traffic lights. It was found that the introduction of a green wave could potentially lower the emissions of the considered air pollutants by $10 \%$ to $40 \%$ in the most favorable conditions, depending on traffic flow and signal timing settings. Sound pressure levels were found to decrease by up to $1 \mathrm{~dB}(\mathrm{~A})$ near the traffic signals, but to increase by up to $1.5 \mathrm{~dB}(\mathrm{~A})$ in between intersections. Traffic intensity and green split were found to have the largest influence on emissions, while the cycle time did not have a significant influence on emissions.
\end{abstract}

Keywords: Urban traffic, Microscopic simulation, Synchronization, Green wave, Sound level, Air pollution

\section{Introduction}

Next to being a major cause of stress for drivers, traffic congestion causes travel delays, and thus imposes a substantional cost on society. It is estimated that every year nearly $1 \%$ of the EU's GDP is lost as a result of this phenomenon (European Commission, 2007). One way to moderate congestion is to expand the road network, but in an urban area this is often not feasible because of the presence of buildings. On the other hand, traffic management solutions-such as introducing and enforcing variable speed limits, installing local-express lanes or reversible lanes, imposing differentiated road pricing or optimizing traffic signal timing - try to improve the performance of the existing infrastructure. Increasingly, new information and communication technologies are used in the implementation of measures, and the deployment of intelligent transport systems is actively promoted by the European Commission (2008).

Optimization of traffic signal parameters has a long history, starting in the late 1950's with the work by Webster (1958) on the timing of isolated intersections based on statistical methods. Since then, the state-of-the-art has evolved over actuated signals, which lengthen the green period to some extent if a queue is observed, to adaptive and cooperative methods, which are realized using actual flow information supplied by traffic detectors, and which involve series of intersections (Bretherton

\footnotetext{
*Corresponding author. Tel.: +329264 9994; fax: +3292649969.

Email address: bert.decoensel@intec.ugent.be (B. De Coensel)
}

et al., 2004; Warberg et al., 2008; Osorio and Bierlaire, 2008). Usually, systems are designed to create green waves along arterial roads facing high demands, and a number of optimization techniques exist in order to accomplish this strategy (e.g., Gartner and Stamatiadis, 2002; Cheng et al., 2006). Because vehicular traffic flow through a network of signalized intersections represents a complex system far from equilibrium, it has been studied extensively from a statistical mechanics point of view, using microscopic traffic simulation models (Chowdhury and Schadschneider, 1999; Brockfeld et al., 2001; Huang and Huang, 2003; Nagatani, 2007, 2009; Varas et al., 2009). Most of the optimization techniques use the average vehicle delay or the number of stops as a measure of effectiveness.

However, there are some conflicts of interest in the selection of objectives for signal timing optimization ( $\mathrm{Li}$ et al., 2004; Warberg et al., 2008). For example, minimizing the delay for vehicles along an arterial road may cause longer waiting times for reverse-flow traffic and for crossing pedestrians; prioritizing public transport (e.g. by skipping a phase) may lower the performance for private transport; optimizing flows may have an impact on the safety of drivers and pedestrians (Tindale and Hsu, 2005; Shinar et al., 2004), etc. Therefore, signal timing optimization is considered to be a multi-objective problem. The potential positive effects of green waves on emissions (noise and air pollutants) are often called upon as an additional support for their introduction. The rationale behind the claim of lowering (air pollutant) emissions is that congestion causes vehicles to function at sub-optimal speeds and accelerations, leading to 
incomplete combustion and additional emissions of $\mathrm{NO}_{\mathrm{x}}, \mathrm{CO}$, etc. Although the potential of green waves to reduce travel delays are widely accepted, the side-effects on vehicle emissions (both noise and air pollutants) are however much less clear.

In this paper, the influence of traffic signal coordination on vehicle emissions will be studied in detail. In particular, a microscopic traffic simulation model is coupled with emission models for noise and air pollutants $\left(\mathrm{CO}_{2}, \mathrm{NO}_{\mathrm{x}}\right.$ and $\left.\mathrm{PM}_{10}\right)$. With this methodology, two options are possible. The first option is to model a limited number of scenarios in great detail (e.g. based on an existing case study setting), thereby including the effect of a large number of contextual factors. The second option is to extract information from the simulation of a large number of (more simplified) scenarios. This option is chosen in the present paper, as it hopefully leads to more general insights, not tied to a particular existing context. The downside is that the effect of only a limited number of factors can be considered, because of computational complexity.

A simplified setting consisting of an urban arterial road with several consecutive signalized intersections will be considered, and through the simulation of a range of scenarios, the influence of traffic demands and signal timing parameters on emissions will be investigated (no air pollutant dispersion modelling is considered). The work discussed in this paper differs from earlier research in several aspects. Noise and air pollutants are considered jointly, and state-of-the-art instantaneous emission models are used for both types of emissions. These emission models were specifically designed for use with microscopic traffic simulation models, and have been validated extensively on a European scale. An important feature of both models is that results are representative for a complete vehicle fleet (in this case the Dutch fleet), instead of representing only a limited sample of vehicle types. Additionally, the ranges of traffic intensities and signal timing parameters are larger than those considered in earlier studies. In Section 2, an overview is given of previous work that considered the influence of traffic signal coordination on noise and air pollutant emissions. In Section 3, the general methodology will be described, including the assumptions and simplifications made. Section 4 will then present the results for a series of scenario simulations, followed by a discussion in Section 5 .

\section{Literature overview}

Research on the influence of traffic light control on noise and air pollutant emission is by no means complete; most studies have considered the emission at a single intersection at mostsee De Coensel et al. (2007) and Pandian et al. (2009) for an overview of literature on noise and air pollutant emissions near traffic intersections. When the effect of traffic signal coordination is considered, usually only the emission of a single vehicle is measured (using on-board equipment), or the immission caused by all vehicles is measured at a few locations. A wide range of methods are used, and often no details are given about the fleet composition, which makes it difficult to compare results across studies.
Based on a review of measurements performed in the UK and Switzerland, Desarnaulds et al. (2004) found that coordination of traffic lights may lower the sound pressure level near intersections by up to $2 \mathrm{~dB}(\mathrm{~A})$. Unal et al. (2003) performed onboard air pollutant emission measurements along a signalized arterial road in North Carolina, US, using four different drivers and eight gasoline fueled light-duty vehicles, before and after the coordination of traffic signals. They found that, depending on the type of vehicle and the level of congestion, the implementation of traffic signal coordination yielded reductions in $\mathrm{HC}$, NO and $\mathrm{CO}$ emissions per unit of distance between 10 and $20 \%$. Zhang et al. (2009) used a portable emission measurement system to compare the $\mathrm{NO}_{\mathrm{x}}, \mathrm{HC}$ and $\mathrm{CO}$ emissions of a single vehicle, when driven along two different roads in Bejing, China, one with and one without coordinated traffic signals (both carried similar traffic flow and composition). It was found that the emission of $\mathrm{HC}$ and $\mathrm{CO}$ per unit of distance was lower along the road with coordinated signals, by resp. $50 \%$ and $30 \%$, but the emission of $\mathrm{NO}_{\mathrm{x}}$ per unit of distance was higher by $10 \%$. A detailed analysis of the driving cycles showed that $\mathrm{NO}_{\mathrm{x}}$ emission increased slightly with increasing average vehicle speed, while $\mathrm{HC}$ and $\mathrm{CO}$ emissions decreased with increasing average vehicle speed. Subsequently, simulations using emission laws extracted from measurements were used to estimate the change in emission that would result from removing the signal coordination along the particular road with coordinated traffic lights. It was found that this action would result in an increase in air pollutant emissions per unit of distance between $9 \%$ and $14 \%$.

A main reason for the relative lack of scientific data on emissions at intersections is that well-controlled field experiments during which emissions are measured are quite complex and expensive to carry out, and therefore not always feasible. On the other hand, computational models for estimating emissions that return realistic results for the stop-and-go behavior of vehicles near intersections have become available recently, for noise (De Coensel et al., 2005, 2007; Can et al., 2008) as well as for air pollutants (Ahn et al., 2002; Int Panis et al., 2006; Silva et al., 2006; Chen and Yu, 2007; Smit et al., 2008; Mensink and Cosemans, 2008; Smit and McBroom, 2009), and these models will become increasingly important for evaluating environmental policies and infrastructural developments.

Considering the case of noise emissions, as part of the SILENCE project, simulations were carried out for a road with three signalized intersections with $200 \mathrm{~m}$ and $500 \mathrm{~m}$ in between (Bérengier and Picaut, 2008). Two situations with coordinated traffic lights were compared: a green wave (cars only have to stop at the first traffic light) and a red wave (all cars have to stop at all traffic lights). Only a single set of traffic light parameters and a single traffic intensity (1440 vehicles/h) were considered. Results indicated that the green wave could lower $L_{\text {Aeq }}$ levels up to $4 \mathrm{~dB}(\mathrm{~A})$ at the intersections, but could increase levels by as much as $3 \mathrm{~dB}(\mathrm{~A})$ between intersections, due to higher average speeds.

Considering the case of air pollutant emissions, early work was performed by Rakha et al. (2000), who used a microscopic traffic simulation model coupled with an instantaneous emis- 
sion model $\left(\mathrm{HC}, \mathrm{CO}\right.$ and $\left.\mathrm{NO}_{\mathrm{x}}\right)$ to assess the influence of the implementation of a green wave along an arterial road with three equally spaced (350 $\mathrm{m}$ apart) traffic signals. They considered the extreme cases of all vehicles having to stop at all signals, and the perfect green wave, and found reductions in emissions in the range of $50 \%$ for the latter. The emission model (instantaneous emissions as a function of speed and acceleration) was obtained through non-linear regression based on measurement data collected for 8 light-duty vehicles under hot stabilized conditions, and did not account for cold starts or high emitters. Zito (2009) used a microscopic traffic simulation model (DRACULA), combined with an artificial neural network (trained on measured data at a monitoring station along the road) to estimate roadside $\mathrm{CO}$ and $\mathrm{C}_{6} \mathrm{H}_{6}$ concentrations near a particular arterial road in Palermo, Italy, which contains a sequence of coordinated traffic lights, spaced $80 \mathrm{~m}$ to $150 \mathrm{~m}$ apart. Using this unconventional model, quite extreme variations in $\mathrm{CO}$ concentration between 0.1 and $1.5 \mathrm{mg} / \mathrm{m}^{3}$, and in $\mathrm{C}_{6} \mathrm{H}_{6}$ concentrations between 0.1 and $4.0 \mu \mathrm{g} / \mathrm{m}^{3}$ were found, depending on the settings for the (common) traffic light cycle time and synchronization offset. Neunhäuserer and Diegmann (2010) used a microscopic traffic simulation model (VISSIM) to extract mean speeds on a 1-minute basis, along an arterial road in Cologne-Mülheim, Germany, containing several signalized intersections over a length of $1 \mathrm{~km}$. Two scenarios, without and with coordinated traffic signals, were considered. Average $\mathrm{NO}_{\mathrm{x}}$ emissions were subsequently estimated for each street section, using a linear combination of driving patterns fitted to the simulated mean speed distributions. Depending on the section considered, they found changes in $\mathrm{NO}_{\mathrm{x}}$ emissions ranging from a decrease by $45 \%$ to an increase by $18 \%$. Finally, Zallinger et al. (2010) also used the VISSIM microscopic traffic simulation model, coupled with an instantaneous emission model (PHEM), to study the effect of signal coordination along an existing arterial road with 12 signalized intersections in Graz, Austria. Simulations showed that optimized signal settings could reduce fuel consumption, $\mathrm{NO}_{\mathrm{x}}$ and $\mathrm{PM}$ emissions by resp. $14 \%, 19 \%$ and $17 \%$. Results were compared with onboard measurements along the actual arterial using 2 cars, and in general a good agreement was found.

Note that the concept of calming green waves (Ellenberg and Bedeaux, 1999) has been proposed with safety purposes in mind, rather than minimizing travel delay. In this case, signal coordination is tuned to encourage drivers to adopt a slower and safer, but more consistent speed by avoiding that drivers accelerate excessively in order to catch up one signalization cycle between two intersections. Based on a reduction of the average speed by 10 to $15 \mathrm{~km} / \mathrm{h}$, a noise reduction of about $3 \mathrm{~dB}(\mathrm{~A})$ could be expected (Ellebjerg, 2007; Bérengier, 2009). However, one concern about this type of signals is that they not only stop traffic that exceeds the speed limit, but also traffic that is not; experimental data suggests that the fraction of unfairly stopped vehicles may be as high as $30 \%$, leading to increases of air pollutants (CO, NO, HC) between $10 \%$ and $40 \%$ (Coelho et al., 2005b). On the other hand, if the speed control traffic signals modify the behavior of the drivers by inducing a speed reduction, they will also result in a decrease in relative pollutant emissions (Coelho et al., 2005a; Barkenbus, 2010). Nevertheless, the effects of calming green waves will not be studied in this work.

\section{Methodology}

Basically, the study of the potential benefits or drawbacks of traffic signal coordination on emissions can be decomposed into an emission related and a traffic related subproblem. The former problem handles about what can be expected in terms of reduction or increase in emissions, depending on factors such as the traffic intensity or traffic signal parameters, but given that the traffic signal coordination works as expected. The latter problem handles about finding those conditions in which coordinated signals are effective in creating a green wave. In this paper, we will mainly focus on the first subproblem. The second subproblem is purely traffic related and has been studied extensively, as already mentioned in the introduction; we will only briefly review some important aspects in the discussion in Section 5.

\subsection{Microscopic traffic simulation}

The aim of the virtual experiment described in this paper is to investigate the influence of signal parameters and traffic intensity on vehicle emissions along a typical urban arterial road with coordinated traffic signals. Traffic simulation models that aim to be accurate in the vicinity of interrupted traffic flows have to model the temporal and spatial behavior of vehicle speeds and accelerations. Microscopic traffic models incorporate these dynamic effects by modelling vehicles individually, and during recent years they have been used successfully as part of traffic noise and air quality prediction models, mostly for scholarly purposes (De Coensel et al., 2005, 2009; Botteldooren et al., 2006; Can et al., 2009; Della Ragione et al., 2009; Zallinger et al., 2010; Madireddy et al., 2011). A traffic network, consisting of an arterial road with signalized intersections, was constructed using Quadstone Paramics (Fritzsche, 1994; Cameron and Duncan, 1996); a schematic view of the setting is shown in Figure 1(left). Note that, because the setting described in this paper is relatively simple, it is expected that the use of a different microscopic traffic simulation model would lead to the same results.

Because it is not feasible to simulate all conceivable configurations of intersections, a number of assumptions and simplifications had to be made. A one-way arterial road with a single lane is considered. As a consequence, the influence of crossflow and reverse-flow traffic, lane changing and overtaking on emissions is neglected. This may lead to an overestimation of the effects; we will discuss the influence of reverse-flow traffic more in detail in Section 5. Not accounting for reverse-flow traffic can be justified given the typical application of signal coordination on urban roads during morning (into the city) or evening (out of the city) rush hour, i.e. periods during which the traffic flow is assumed to be dominant in a single direction. For the same reason, not accounting for cross-flow traffic can be somewhat justified, at least when arterial roads not too close to 

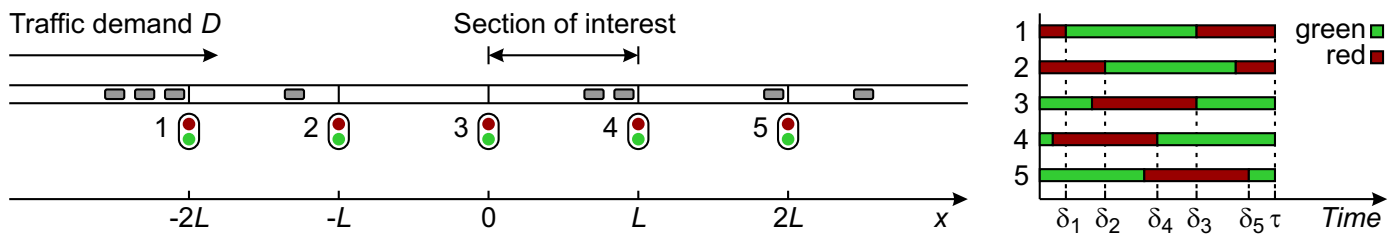

Figure 1: Schematic view of the simulated arterial road (left), together with an example of unsynchronized traffic light timing (right).

the urban core are considered. The modelled arterial road has a traffic demand $D$ [vehicles $/ \mathrm{h}$ ] and a speed limit $v_{\max }=50 \mathrm{~km} / \mathrm{h}$, which is typical for urban roads in Europe. Five traffic signals are located at regular distances $L=200 \mathrm{~m}$ from each other. This distance was chosen to be realistic for urban situations, and results in only minimal platoon dispersion, occurring when vehicles leave a signalized intersection. Additionally, given the urban rush hour context, only a single light duty vehicle type is used for the traffic simulation. Nevertheless, emission calculations are representative for a complete vehicle fleet of light duty vehicles (see Sections 3.3 and 3.4).

Vehicle behavior parameters, such as the aggression, awareness and reaction time distributions of the drivers, the queue gap distance, the mean target headway between a vehicle and the car in front, the distance at which signposting is perceived etc., were not varied in this study. In order to adhere to a generic methodology, default Paramics values were used, which are already carefully selected based on extensive measurements (Fritzsche, 1994). Although these parameters have an influence on traffic dynamics (Helbing, 2001; Knospe et al., 2002), they are highly dependent on specific configurations of infrastructure and even on social and cultural aspects. These parameters could be adjusted for specific cases to which the methodology described in this paper is applied.

The simulation time considered, noted $T_{\text {sim }}$, was 1 hour, with a simulation timestep $\Delta t=0.2 \mathrm{~s}$. However, the actual simulations included two additional 5-minute periods: one at the beginning, for traffic build up, and one at the end, to make sure all vehicles can complete their trip. Actual simulated traffic flows $Q$ [vehicles/h] and travel times are calculated on the basis of the trips that are started during the considered 1-hour period. Vehicles are loaded onto the network at a distance of $500 \mathrm{~m}$ from the first traffic signal (western side in Figure 1), randomly distributed in time according to a negative exponential distribution. Because of the statistical nature of microsimulation, results differ between runs of the model: the actual simulated traffic flow $Q$ will, in each particular simulation run, be near the demanded value $D$, but will not necessarily be exactly the same. In particular, when the demand is higher than the capacity of the road, the actual flow will reach a saturation value.

\subsection{Traffic signal timing}

The main parameters controlling the operation of a single, isolated signalized intersection are the cycle time $\tau[\mathrm{s}]$, the green split $\alpha_{i}$ for the different approaches $i$ of the intersection, and the offset $\delta$ [s]. The cycle time is defined as the sum of the durations of all distinct phases of the signalized intersection, where a phase corresponds to a particular state of the traffic lights. In other words, it is the time it takes for a traffic signal to get from the start of the green light through amber and red to the start of the next green light. For isolated signalized intersections, a short cycle time will generally lead to lower average delays (vehicles never have to wait long for a green light), but will lower the overall capacity of the intersection (Webster, 1958). Upper and lower bounds for the cycle time are also set by safety concerns: if the cycle time is too long, drivers may start to ignore the red phase; if it is too short, there is an increased risk of collisions (Warberg et al., 2008). The green split for the $i$ 'th approach of a single signalized intersection is defined as the ratio between the amount of green time $\gamma_{i}$ [s] and the cycle time, i.e. $\alpha_{i}=\gamma_{i} / \tau$. The green split is usually divided among the different approaches of an intersection according to the traffic intensity expected for each approach; arterial roads are given the larger split. The offset of a signalized intersection is defined as the difference in time between the start of a cycle of this intersection and the start of a cycle of some reference intersection. The offset is used to provide signal coordination between consecutive intersections for vehicles travelling along an arterial road. Next to these main parameters, the operation of a signalized intersection is also characterized by the order of the phases during a cycle (called the phase sequence). The influence of the phase sequence was not taken into account in this work, because the intersections that are considered only have a single approach.

When an isolated intersection is considered, the cycle time and green split are usually optimized in order to minimize the average vehicle delay; the method developed by Webster (1958) is widely used for this. However, the cycle time and green split of the intersections considered in this work were not optimized, because the optimal settings depend on the amount of crossflow traffic, which is not taken into account in this work. Rather, a range of settings is considered, in order to make the results applicable to a range of cross-flow traffic intensities.

When a series of intersections is considered, as in the present study, signal coordination is usually accomplished through the use of a common cycle time (which can be time-dependent). Both pretimed and adaptive signals can be used to install green waves (Warberg et al., 2008). The former use static plans for the signal parameters and offsets, according to the time of day. The latter are set to work together and periodically adjust their settings in order to minimize travel delays, based on detection and short-term prediction of traffic intensities. It turns out that, in order to avoid transient side-effects such as malfunctioning green waves, changes to the signal settings should be made in small steps only (Bretherton et al., 2004). It is assumed that 
Table 1: Parameter ranges for the simulation scenarios.

\begin{tabular}{lll} 
Parameter & Range & Levels \\
\hline$\tau$ & $30,40 \ldots 90 \mathrm{~s}$ & 7 \\
$\alpha$ & $0.5,0.6,0.7,0.8$ & 4 \\
$D$ & $50,100 \ldots 2000$ vehicles/h & 40 \\
Signal scheme & green, red, desynchronized & 3 \\
\hline
\end{tabular}

these changes are small enough to not have an influence on emissions, so it is sufficient to consider the stationary state in this work. The traffic signals at all intersections are considered to operate with a common cycle time $\tau$ and green split $\alpha$ for the arterial road (west to east), and with offsets $\delta_{i}, 1 \leq i \leq 5$. To further simplify the discussion, no amber time is considered, i.e. the green time for each intersection is $\alpha \tau$, and the red time is $(1-\alpha) \tau$. An example of the signal settings of the five signalized intersections is given in Figure 1(right).

A series of scenarios was created by varying the parameters $\tau, \alpha$ and $D$; an overview of the parameter ranges can be found in Table 1. Next to this, three different traffic signal coordination schemes were considered, labeled green, red and desynchronized. In the first scheme, the offsets are set to create a green wave, i.e. $\delta_{i}=3.6 L / v_{\max } \cdot i$. Vehicles will only have to stop at the first traffic light, with probability $1-\alpha$. Note that this scheme represents the theoretical extreme; in practice a perfect green wave will be hard to achieve (see Section 5 for a discussion). In the second scheme, the offsets are set to create a red wave, i.e. $\delta_{i}=\left(3.6 L / v_{\max }-\alpha \tau\right) \cdot i$. Vehicles will have to stop at every traffic light. In the third scheme, the offsets are set randomly, and in order to desynchronize the signals, a small but random number of seconds $(<2 s)$ is added to or subtracted from the cycle times. This way, a wide range of waiting times and queue lengths at each intersection is encountered over the course of a simulation run; the chance that a vehicle will have to stop at a single traffic light will again roughly be $1-\alpha$. The results for the desynchronized scheme thus represent the average over the results for all possible schemes in which there is no signal coordination. Finally, the total number of unique traffic scenarios is equal to $7 \times 4 \times 40 \times 3=3360$.

\subsection{Noise emission modelling}

The output of a microscopic traffic simulation run consists of the instantaneous position, speed and acceleration of each vehicle at each timestep. Subsequently, the instantaneous noise emission of each vehicle in the simulation is calculated using the Imagine road traffic noise emission model (Peeters and van Blokland, 2007). This model was specifically developed with microscopic traffic simulation in mind, and has been validated widely on a European scale, using measurements on a large number of vehicles, driven on a wide range of road surface types. The model forms the basis for a potential future $\mathrm{Eu}-$ ropean standard for road traffic noise prediction, and was calibrated to generate the average noise emission of the European vehicle fleet. More in particular, while there may be differences between different types of vehicles in terms of noise emission, the model will provide a good estimation of traffic sound levels, when results are aggregated over a sufficiently large number of vehicles sampled from the European fleet. Regional differences can be accounted for through corrections on the reference road surface (e.g. the use of porous asphalt) and on standard vehicle fleet characteristics (e.g. higher fraction of diesel vehicles). Reference values were used in this work, which makes the results valid for the light duty vehicles of the Dutch vehicle fleet. The light duty vehicle type considered in this work corresponds to the Imagine emission category 1.

The Imagine model produces instantaneous point source sound power levels, in which two sources of noise are considered separately: rolling noise (generated by tire-road interaction and aerodynamic drag) and propulsion noise (generated by the powertrain and the exhaust). Both contributions are resp. given by the following formulae (Peeters and van Blokland, 2007):

$$
\begin{gathered}
L_{W, R}(v, a)=A_{R}+B_{R} \cdot \log _{10}\left(\frac{v}{v_{r e f}}\right), \\
L_{W, P}(v, a)=A_{P}+B_{P} \cdot\left(\frac{v-v_{r e f}}{v_{r e f}}\right)+C_{P} \cdot a,
\end{gathered}
$$

where $v$ is the vehicle speed (in $\mathrm{km} / \mathrm{h}$ ) with $v_{\text {ref }}=70 \mathrm{~km} / \mathrm{h}$, and $a$ is the vehicle acceleration (in $\mathrm{m} / \mathrm{s}^{2}$ ). For values of the coefficients $A_{R}, B_{R}, A_{P}, B_{P}$ and $C_{P}$, we refer to Peeters and van Blokland (2007). Both contributions are then aggregated to obtain the total sound power level, in $\mathrm{dB}(\mathrm{A})$, produced by a vehicle:

$$
L_{W}(v, a)=10 \log _{10}\left(10^{L_{W, R}(v, a) / 10}+10^{L_{W, P}(v, a) / 10}\right) .
$$

Note that instantaneous emissions are calculated on a $1 / 3$ octave band basis; however, in this work we will only consider the A-weighted value.

When the noise emission of a vehicle trip through the network is considered, we define the total sound power level $L_{W}^{\text {tot }}$ of the particular vehicle over the course of its trip:

$$
L_{W}^{t o t}=10 \log _{10}\left(\frac{\Delta t}{1 \mathrm{~s}} \sum_{t} 10^{L_{W}(t) / 10}\right),
$$

in which the summation is calculated over all simulation timesteps that the vehicle needs to complete its trip (i.e. $T / \Delta t$ values, with $T$ the duration of the trip, in seconds). Trip results averaged over all simulated vehicles are noted $\left\langle L_{W}^{\text {tot }}\right\rangle$. This quantity relates directly to the sound power level used for noise mapping purposes, and as such relates to time-averaged immission levels. In particular, the hourly averaged A-weighted sound power level emitted by the simulated road segment equals $\left\langle L_{W}^{t o t}\right\rangle+10 \log _{10}(Q)$.

Because of the local character of sound, it may also be useful to consider the (hourly) equivalent continuous (A-weighted) sound pressure level $L_{\text {Aeq }}$ at a number of locations along the simulated road segment. In particular, we will consider two receiver locations, one in the middle between traffic lights 3 and $4(x=L / 2)$ and one near traffic light $4(x=L)$, both at a standardized height $(1.5 \mathrm{~m})$ and distance from the road $(7.5 \mathrm{~m})$. The hourly $L_{\mathrm{Aeq}}$ is derived from the time series of 
instantaneous sound pressure levels (which in turn is caused by the instanteneous sound power level of all vehicles on the road segment), and is calculated assuming free field propagation conditions and only considering geometric divergence. The $L_{\mathrm{Aeq}}$ at both locations will strongly depend on the traffic intensity; for further analysis, we therefore also define the average contribution to the sound pressure level by a single vehicle as $\left\langle L_{\text {Aeq }}\right\rangle=L_{\text {Aeq }}-10 \log _{10}(Q)$. Note that differences in $\left\langle L_{\text {Aeq }}\right\rangle$ will also reflect differences in $L_{\mathrm{Aeq}}$ at the same traffic flow.

Finally, it has to be noted that, given the urban rush hour context, only light duty vehicles are considered in this study, as already mentioned in Section 3.1. For heavy duty vehicles, acceleration has a more pronounced effect on noise emission, which is not the case for light duty vehicles, due to the engine noise being more controlled. Consequently, if the vehicle fleet composition consists of a significant amount of heavy duty vehicles, higher noise levels could be expected near the intersections for the red wave scheme, which would increase the beneficial effect of a green wave on noise levels near the intersections.

\subsection{Air pollutant emission modelling}

The instantaneous $\mathrm{CO}_{2}, \mathrm{NO}_{\mathrm{x}}$ and $\mathrm{PM}_{10}$ emission of each vehicle in the simulation is calculated using the VERSIT $+{ }^{\text {micro }}$ vehicle exhaust emission model. The VERSIT + model, developed by TNO (Smit et al., 2005, 2007), is based on more than 12,500 measurements on vehicles of a wide range of makes and models, fuel types, Euro class, fuel injection technology, types of transmission etc. The model uses multivariate regression techniques to determine emission factor values for different vehicle classes. As the model requires actual driving pattern data as input, it is fully capable of modelling the effects of congestion on emission. Furthermore, it takes into account detailed effects such as cold started engines; the emission factors for $\mathrm{PM}_{10}$ also account for non-exhaust emissions, the wearing of tires and brakes etc. A derived model, VERSIT $+{ }^{\text {micro }}$, was recently developed by TNO (Ligterink and De Lange, 2009), specifically targeted at a coupling with microscopic traffic simulation models. For this, emission parameters of different vehicles (with varying fuel type) were aggregated into a prototypical vehicle emission model representing the average emission of the Dutch vehicle fleet. This procedure is similar to the one used in the construction of the Imagine noise emission model, and as such, the model will correctly predict measurement results aggregated over a sufficiently large number of vehicles sampled from the Dutch fleet. In this work, the VERSIT $+{ }^{\text {micro }}$ light duty vehicle class representing the light duty vehicles within the fleet in Dutch urban environments during the year 2009 was used.

The VERSIT $+{ }^{\text {micro }}$ model produces instantaneous vehicle emissions in $\mathrm{g} / \mathrm{s}$, on the basis of instantaneous speed $v$ and acceleration $a$, extracted from the microscopic traffic simulation runs. First, a dynamic variable $w$ is defined as (Ligterink and De Lange, 2009):

$$
w=a+0.014 \cdot v .
$$

For constant $w$, emissions were found to vary only slowly with speed. Hence, the remaining dependence on $v$ was set in three categories, roughly corresponding to urban, rural and freeway driving (idling is considered apart). Subsequently, three dynamic domains (stationary, dynamic and aggressive) are set for each speed category. Finally, the emissions $e$ in $\mathrm{g} / \mathrm{s}$ are given by the following set of piecewise linear equations (Ligterink and De Lange, 2009):

$$
e= \begin{cases}u_{0} & (v<5, a<0.5), \\ u_{1}+u_{2}|w|_{+}+u_{3}|w-1|_{+} & (v<50), \\ u_{4}+u_{5}|w|_{+}+u_{6}|w-1|_{+} & (50<v<80), \\ u_{7}+u_{8}\left|w-\frac{1}{2}\right|_{+}+u_{9}\left|w-\frac{3}{2}\right|_{+} & (v>80),\end{cases}
$$

where the function $|x|_{+}$yields 0 for $x<0$, and $x$ otherwise. The first line in Eq. 6 models the air pollutant emissions during idling. The 10 coefficients $u_{i}$ in each of the regions of the speed-acceleration space were, for each air pollutant type, determined through a maximum likelihood method. Similar to the case of noise emission, we will note the total $\mathrm{CO}_{2}, \mathrm{NO}_{\mathrm{x}}$ and $\mathrm{PM}_{10}$ emission (in $\mathrm{g}$ ) of a vehicle trip through the network as $\mathrm{CO}_{2}^{\text {tot }}, \mathrm{NO}_{\mathrm{x}}^{\text {tot }}$ and $\mathrm{PM}_{10}^{\text {tot }}$, and the trip results averaged over all simulated vehicles as $\left\langle\mathrm{CO}_{2}^{\text {tot }}\right\rangle,\left\langle\mathrm{NO}_{\mathrm{x}}^{\text {tot }}\right\rangle$ and $\left\langle\mathrm{PM}_{10}^{\text {tot }}\right\rangle$. To get the hourly emitted amount of air pollutants on the simulated road segment, one has to multiply the latter quantities by $Q$.

\section{Simulation results}

\subsection{Road capacity and travel times}

One of the principal questions to ask when determining if signal coordination would be advisable, is to see what trade-offs exist between road capacity, travel times and vehicle emissions, as this would enable traffic engineers to devise suitable compromise solutions. Therefore, we first present the influence of signal coordination on road capacity and travel times. Figure 2 shows the traffic flow $Q$ as a function of traffic demand $D$. The capacity of the road (including all signalized intersections) can be defined as the limit value of $Q$ for high $D$. It can be seen that, for most part, capacity depends on the green split, and that installing the green wave slightly increases the road capacity, by about $6 \%$. This is somewhat lower than what is found empirically (e.g., Lum et al. (1998) found an increase of about $8.4 \%$ ), which is probably due to the simple layout and limited size of the simulated network. Because of the small influence of the cycle time, the results shown in Figure 2 are averaged over the different cycle times for the purpose of clarity. It was found that there is no significant difference between the desynchronized scheme and the red wave scheme $(p>0.1)$. This means that implementing the red wave scheme will not lower the capacity significantly as compared to the case without coordination, even if this scheme results in more stops. The fact that having a red wave does not lower capacity as compared to the case without signal coordination can be easily understood when one takes into account that road capacity is determined by the main bottleneck: when there is no signal coordination, one can assume that at least one of the traffic lights will generate a bottleneck, where most vehicles have to stop because of bad timing between two consecutive lights. More in particular, this result suggests that signal coordination in one direction 


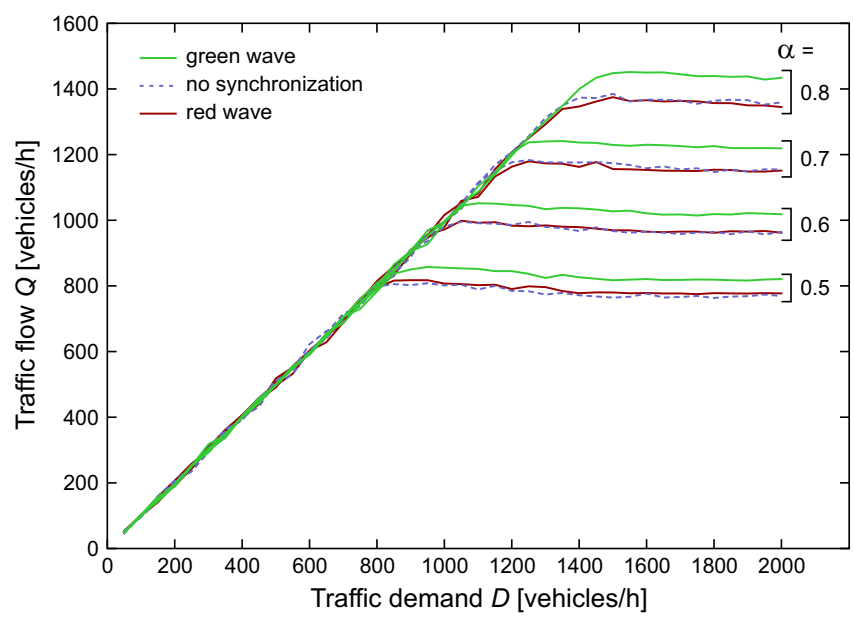

Figure 2: Traffic flow, as a function of traffic demand, for various signal coordination schemes and green split. Results are averaged over the different cycle times.

will not have an adverse effect on road capacity in the opposite direction, at least for the theoretical situations considered in this work. It has to be noted that the scenarios considered do not contain any downstream obstructions; as such, the capacity of the simulated road is mainly determined by the traffic signal timings (which are the same for all traffic signals, except for the offsets). Therefore, effects of (over)saturation are mainly visible in front of the first traffic signal; further down the simulated road, traffic is always in undersaturated conditions.

When travel times for vehicles crossing the whole network are considered, results will also be partly determined by the behavior of vehicles in front of the first traffic signal, for which the signal coordination scheme does not make a difference. In order to assess the influence of the different coordination schemes, we will therefore focus, for the remainder of this work, on a particular section of interest, from stopline to stopline between the third and fourth traffic signal (see Figure 1). This section has a length of $200 \mathrm{~m}$ and contains an acceleration, a cruising and a queueing zone. Results for this section of interest will reflect the influence of the green wave normalized to a single traffic light. At the given speed limit of $50 \mathrm{~km} / \mathrm{h}$, it takes at least $14.4 \mathrm{~s}$ for a vehicle to cross this section. In Figure 3, average travel times for the section of interest are given as a function of $\alpha$ and $\tau$, aggregated over the different actual traffic flows $Q$. For the green wave scheme, travel times for the section of interest were found to be independent of $\alpha, \tau$ and $Q$, as long as the road is not saturated, as can be expected (therefore, results for the green wave scheme are averaged over $\alpha$ in Figure 3). For the other schemes, travel times increase with increasing cycle time and with decreasing green split. The values for the red wave scheme can be easily understood; e.g. in case $\tau=30 \mathrm{~s}$ and $\alpha=0.5$, vehicles have to stop for $15 \mathrm{~s}$ on average, resulting in an average travel time of $29.4 \mathrm{~s}$ for the section of interest.

A stepwise multiple linear regression analysis was performed with travel time as dependent variable, and $\alpha, \tau$ and $Q$ as independent variables, for the desynchronized scheme. It was found



Figure 3: Average travel time for the section of interest, for various signal coordination schemes, as a function of cycle time and green split. Results are averaged over the different traffic flows, and for the green wave scheme also over the green split.

that the green split explains about $37.2 \%$ of variance in travel time, the traffic flow an additional $22.1 \%$, and the cycle time an additional $10.8 \%\left(r^{2}=0.70\right)$. Given the average travel time of $14.6 \mathrm{~s}$ over the section of interest in the green wave scheme, one gets the following regression formula for the effect of installing a green wave on the average travel time $\left\langle T_{s}\right\rangle$, per traffic signal:

$$
\Delta\left\langle T_{s}\right\rangle=-24.1+41.3 \cdot \alpha-10.3 \cdot \frac{\tau}{100}-16.6 \cdot \frac{Q}{2000} .
$$

Note that this formula is only valid for the parameter ranges as given in Table 1, and for a limit speed of $50 \mathrm{~km} / \mathrm{h}$ and a distance of $200 \mathrm{~m}$ between traffic lights. However, in first approximation, Eq. 7 can also be used for larger distances between traffic lights, if one assumes that vehicles drive at the free flow speed over the additional distance, and that this free flow speed is independent of the signal coordination scheme.

\subsection{Noise emission}

Figure 4 shows the total emitted sound power level, averaged over all simulated vehicles, and only considering the section of interest, as a function of traffic flow and signalization scheme. It can be seen that introducing traffic signal coordination will increase the total noise emission in all cases except for very low traffic flows, and this increase will be larger for high traffic flows, up to a value of $0.6 \mathrm{~dB}(\mathrm{~A})$. The implementation of a green wave will reduce the number of vehicles decelerating/accelerating near the traffic signals, but will also increase the average vehicle speed; from Figure 4 one can conclude that the decrease in noise emission caused by the former effect is more than compensated by the increase in noise emission caused by the latter effect. Note that for heavy duty vehicles, the engine, drive train, and exhaust noise are more important components of the total noise emission. Thus, when traffic consists of a relatively large fraction of heavy vehicles (not considered in this work), it can be expected that introducing traffic signal coordination will lead to a lower increase of the total noise emission. Finally, the difference between the two extreme cases 


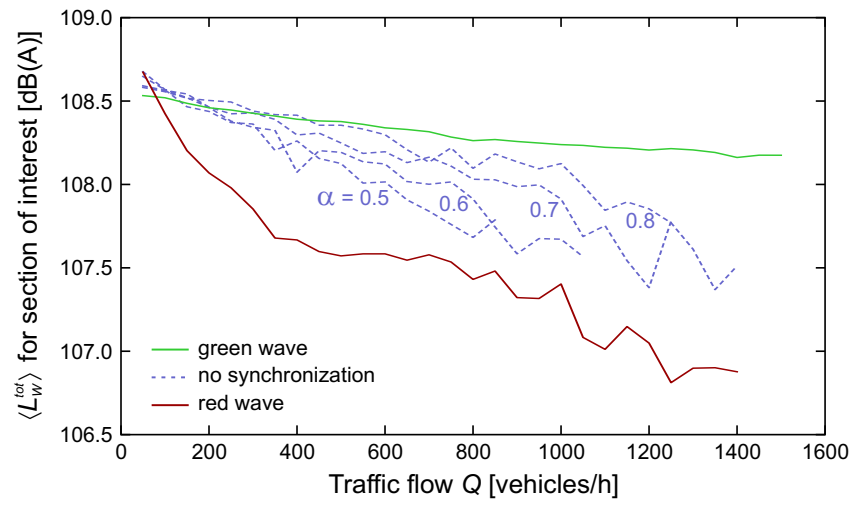

Figure 4: Average total sound power level emitted per vehicle for the section of interest, as a function of traffic flow, for various signal coordination schemes and green split $\alpha$. Results are averaged over the different cycle times, and for the green and red wave schemes also over the green split.

of a green wave and a red wave can be up to $1.2 \mathrm{~dB}(\mathrm{~A})$ for high traffic flows.

A stepwise multiple linear regression analysis was performed with $\left\langle L_{W}^{\text {tot }}\right\rangle$ as dependent variable, and $\alpha, \tau$ and $Q$ as independent variables, for the green wave scheme. It was found that the traffic flow $Q$ explains about $83.2 \%$ of variance, and the green split $\alpha$ an additional $4.4 \%\left(r^{2}=0.88\right)$. The cycle time $\tau$ did not have a significant influence on $\left\langle L_{W}^{\text {tot }}\right\rangle$ in this scheme. The same analysis was performed for the scheme without synchronization: $Q$ explains about $72.5 \%$ of variance in this scheme, and $\alpha$ an additional $6.1 \%\left(r^{2}=0.79\right)$. Again, $\tau$ did not have a significant influence on $\left\langle L_{W}^{t o t}\right\rangle$. By subtracting both regression equations, one gets the following formula for the effect of installing a green wave on the average total sound power level emitted per vehicle, in $\mathrm{dB}(\mathrm{A})$ :

$$
\Delta\left\langle L_{W}^{t o t}\right\rangle=0.25-0.59 \cdot \alpha+1.19 \cdot \frac{Q}{2000} .
$$

The same restrictions as for Eq. 7 have to be taken into account when using this and subsequent regression equations. Additionally, these results are only calculated for the considered vehicle fleet (Sections 3.3 and 3.4). Note that Eq. 8 also equals the increase in hourly averaged A-weighted sound power level emitted on the road segment associated to the section of interest, because the additional term $10 \log _{10}(Q)$ vanishes.

The analysis in the previous paragraphs considered the total noise emission over the section of interest. However, the effect of a green wave on the sound pressure level may vary depending on the measurement location (Bérengier and Picaut, 2008). Figures 5 and 6 show the average contribution to the $L_{\text {Aeq }}$ by a single vehicle, resp. in between traffic lights and near a traffic light, at a distance of $7.5 \mathrm{~m}$ from the road. It is found that the implementation of a green wave will result in a decrease of $\left\langle L_{\text {Aeq }}\right\rangle$ (and consequently of $L_{\mathrm{Aeq}}$ ) by up to $1 \mathrm{~dB}(\mathrm{~A})$ near the signalized intersections ( $1.5 \mathrm{~dB}(\mathrm{~A})$ if compared to the red wave scheme), but will result in an increase of $L_{\text {Aeq }}$ by up to $1.5 \mathrm{~dB}(\mathrm{~A})$ between intersections ( $2 \mathrm{~dB}(\mathrm{~A})$ if compared to the red wave scheme), because of the higher average vehicle speeds. When one takes

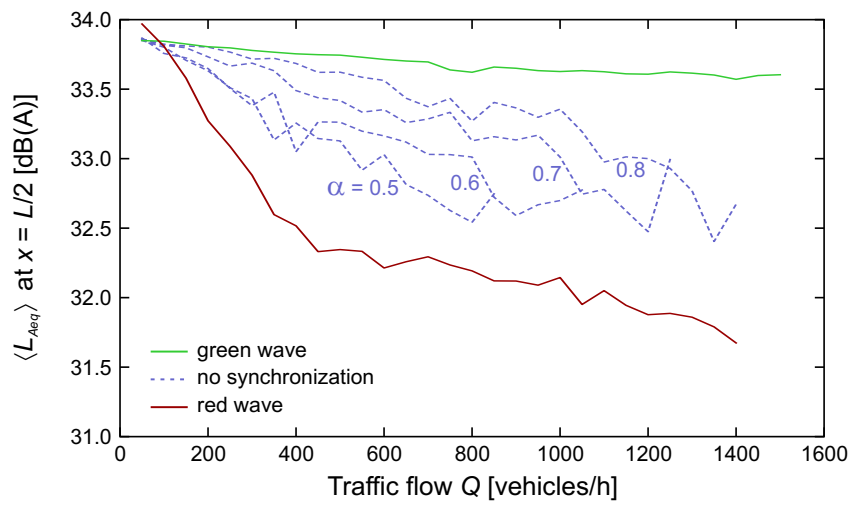

Figure 5: Average contribution of a single vehicle to the $L_{\mathrm{Aeq}}$, at location $x=$ $L / 2$ (in between traffic lights 3 and 4 ), as a function of traffic flow, for various signal coordination schemes and green split $\alpha$. Results are averaged over the different cycle times, and for the green and red wave schemes also over the green split.

into account the fact that the absolute value of the effect will be larger when the microphone is placed closer to the road, these extremes are roughly in accordance with empirical results found in literature (Desarnaulds et al., 2004). From Figures 5 and 6 it also follows that a green wave will have the least deteriorating effect on noise levels when traffic intensities are low. For higher intensities, the decrease in level near the signalized intersections will be somewhat less, while in between intersections, the increase in level will clearly be higher.

Although the results in Figures 5 and 6 are qualitatively comparable to the simulation results reported by Bérengier and $\mathrm{Pi}$ caut (2008) ( $4 \mathrm{~dB}(\mathrm{~A})$ decrease near intersections, $3 \mathrm{~dB}(\mathrm{~A})$ increase in between intersections as compared to the red wave scheme), the absolute values are somewhat smaller. In order to make a direct comparison possible, two additional scenario simulations were carried out for a network that reproduces the setting as used by Bérengier and Picaut (2008). In particular, the same distances between intersections, the same green wave and red wave traffic light timings, and the same traffic flow were used (see Section 2 for more details). A decrease by $1.1 \mathrm{~dB}(\mathrm{~A})$ was found near the intersections, while a maximal increase by $1.7 \mathrm{~dB}(\mathrm{~A})$ was found in between intersections. A closer look at the results showed that for a large part, these differences can be linked to the LCPC vehicle noise emission model (David, 2000) used by Bérengier and Picaut (2008). Only a single vehicle type was considered (Renault Clio 1.41), as compared to a whole vehicle fleet in the present paper. More importantly, the LCPC model pronounces much more the effect of acceleration on emission, as compared to the Imagine model, which leads to higher noise levels near the intersections in the red wave scheme.

\subsection{Air pollutant emission}

Figures 7, 8 and 9 resp. show the average amount of $\mathrm{CO}_{2}$, $\mathrm{NO}_{\mathrm{x}}$ and $\mathrm{PM}_{10}$ that vehicles emit while travelling over the section of interest, as a function of traffic flow, for various signal coordination schemes and green split $\alpha$. It was chosen to 


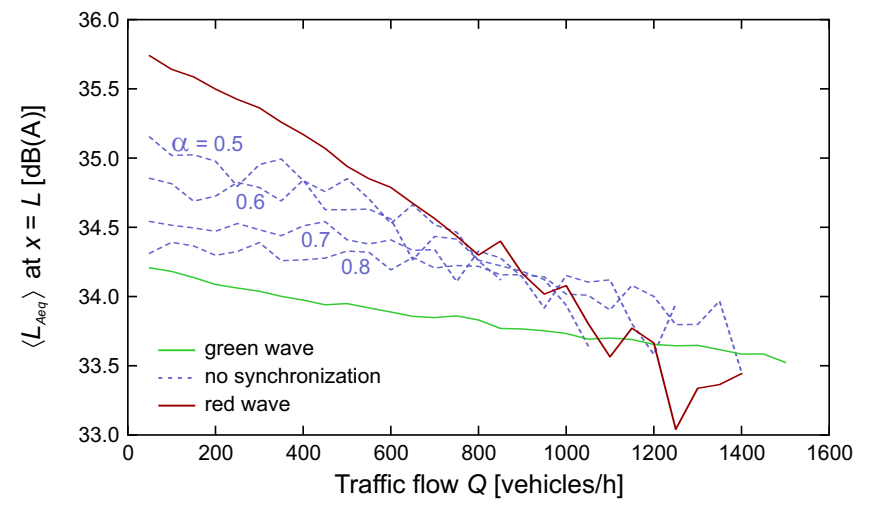

Figure 6: Average contribution of a single vehicle to the $L_{\mathrm{Aeq}}$, at location $x=L$ (near traffic light 4), as a function of traffic flow, for various signal coordination schemes and green split $\alpha$. Results are averaged over the different cycle times, and for the green and red wave schemes also over the green split.

present the results in $\mathrm{g}$ rather than in $\mathrm{g} / \mathrm{km}$ or $\mathrm{g} / \mathrm{s}$, such that the figures represent the absolute effect per intersection. In order to get the average emissions in $\mathrm{g} / \mathrm{km}$, or to get the total air pollutant emission per $\mathrm{km}$ and per hour, one has to multiply the values in these figures by resp. a factor 5 or $5 Q$. One can see that, in contrast to the case of noise emissions, all types of air pollutant emissions decrease when a green wave is installed. This is in accordance with most results reported in Section 2, except for the case of $\mathrm{NO}_{\mathrm{x}}$ emissions, for which reported measurement results were less clear and a potential increase was found in some situations. This may be due to the fact that $\mathrm{NO}_{\mathrm{x}}$ emissions are more related to cilinder head temperature than to the occurrence of incomplete combustion, and thus are less correlated with average vehicle speed than the other types of emissions. In the present simulations, because instantaneous acceleration has a large influence on air pollutant emission, a potential increase of emissions caused by the increase in average vehicle speed is more than compensated by the smoother traffic flow resulting from the coordinated traffic signals. Irrespective of the type of air pollutant, the difference in average emission between the desynchronized scheme and the red wave scheme reduces to zero for traffic flows close to capacity. This is caused by the influence of idling vehicles in the queue in front of a traffic light: while idling vehicles still emit a considerable amount of noise, the fraction of total air pollutant emission caused by idling vehicles is relatively small.

A stepwise multiple linear regression analysis was performed, resp. with $\left\langle\mathrm{CO}_{2}^{\text {tot }}\right\rangle,\left\langle\mathrm{NO}_{\mathrm{x}}^{\text {tot }}\right\rangle$ and $\left\langle\mathrm{PM}_{10}^{\text {tot }}\right\rangle$ as dependent variables, and $\alpha, \tau$ and $Q$ as independent variables, for the desynchronized scheme. It was found that the green split $\alpha$ explains resp. about $41.0 \%, 54.1 \%$ and $25.4 \%$ of variance, and that the traffic flow $Q$ resp. explains $25.2 \%, 11.5 \%$ and $40.8 \%$ of variance additionally ( $r^{2}=0.66$ for all pollutant types). Irrespective of the type of air pollutant, the cycle time $\tau$ did not have a significant influence on emissions. The following regression equations are found for the average air pollutant emission per vehicle for the section of interest, in $\mathrm{g}$, for the desynchronized

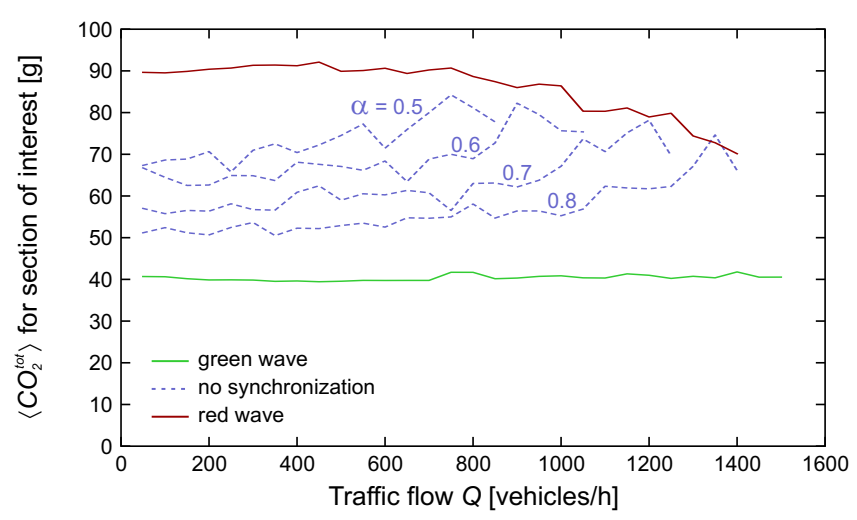

Figure 7: Average $\mathrm{CO}_{2}$ emission per vehicle for the section of interest, as a function of traffic flow, for various signal coordination schemes and green split $\alpha$. Results are averaged over the different cycle times, and for the green and red wave schemes also over the green split.

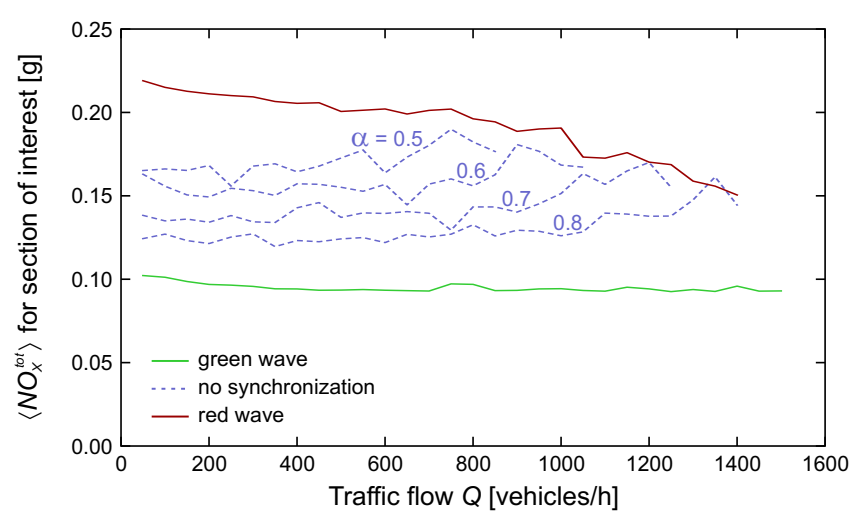

Figure 8: Average $\mathrm{NO}_{\mathrm{x}}$ emission per vehicle for the section of interest, as a function of traffic flow, for various signal coordination schemes and green split $\alpha$. Results are averaged over the different cycle times, and for the green and red wave schemes also over the green split.

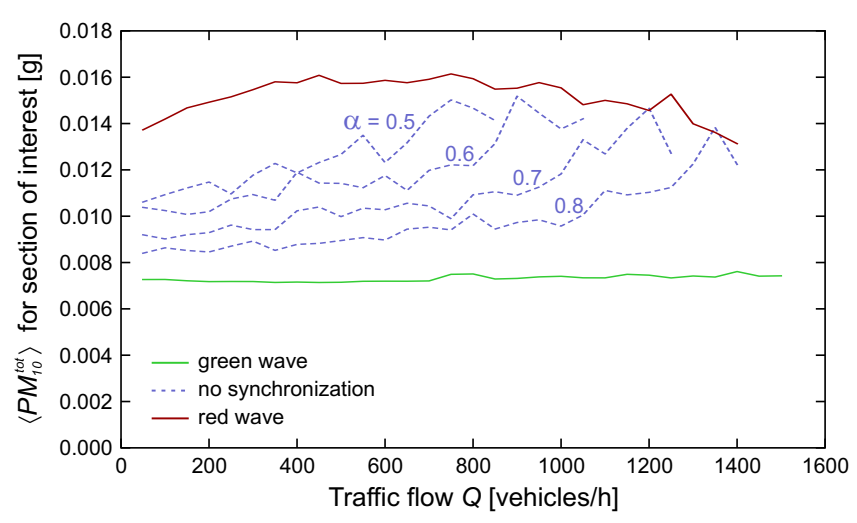

Figure 9: Average $\mathrm{PM}_{10}$ emission per vehicle for the section of interest, as a function of traffic flow, for various signal coordination schemes and green split $\alpha$. Results are averaged over the different cycle times, and for the green and red wave schemes also over the green split. 
(subscript $d$ ) scheme:

$$
\begin{gathered}
\left\langle\mathrm{CO}_{2}^{\text {tot }}\right\rangle_{d}=102.7-70.1 \cdot \alpha+28.4 \cdot \frac{Q}{2000}, \\
\left\langle\mathrm{NO}_{\mathrm{x}}^{\text {tot }}\right\rangle_{d}=0.241-0.156 \cdot \alpha+0.040 \cdot \frac{Q}{2000}, \\
\left\langle\mathrm{PM}_{10}^{\text {tot }}\right\rangle_{d}=0.0173-0.0126 \cdot \alpha+0.0074 \cdot \frac{Q}{2000} .
\end{gathered}
$$

A similar regression analysis was performed for the average emission per vehicle in the green wave scheme; it was found that neither of the variables $Q, \alpha$ or $\tau$ had a significant influence on emissions, as can also be seen in Figures 7-9. The average values for $\left\langle\mathrm{CO}_{2}^{\text {tot }}\right\rangle_{g},\left\langle\mathrm{NO}_{\mathrm{x}}^{\text {tot }}\right\rangle_{g}$ and $\left\langle\mathrm{PM}_{10}^{\text {tot }}\right\rangle_{g}$ are resp. $40.2 \mathrm{~g}, 0.095 \mathrm{~g}$ and $0.0073 \mathrm{~g}$ for the section of interest of $200 \mathrm{~m}$ length. A similar regression analysis was also performed for the average emission per vehicle in the red wave scheme; it was found that only the traffic flow $Q$ had a significant influence on emissions, explaining $72.5 \%, 90.6 \%$ and $89.3 \%$ of variance for resp. $\mathrm{CO}_{2}, \mathrm{NO}_{\mathrm{x}}$ and $\mathrm{PM}_{10}$ emissions. The following regression equations are found for the average air pollutant emission per vehicle for the section of interest, in $\mathrm{g}$, for the red wave (subscript $r$ ) scheme:

$$
\begin{gathered}
\left\langle\mathrm{CO}_{2}^{\text {tot }}\right\rangle_{r}=95.5-25.9 \cdot \frac{Q}{2000}, \\
\left\langle\mathrm{NO}_{\mathrm{x}}^{\text {tot }}\right\rangle_{r}=0.225-0.089 \cdot \frac{Q}{2000}, \\
\left\langle\mathrm{PM}_{10}^{\text {tot }}\right\rangle_{r}=0.0137+0.0134 \cdot \frac{Q}{2000}-0.0199 \cdot\left(\frac{Q}{2000}\right)^{2} .
\end{gathered}
$$

Finally, one may calculate the effect of installing a green wave on the average air pollutant emission per vehicle and per traffic signal, in $\mathrm{g}$, as $\Delta\left\langle\mathrm{CO}_{2}^{\text {tot }}\right\rangle=\left\langle\mathrm{CO}_{2}^{\text {tot }}\right\rangle_{g}-\left\langle\mathrm{CO}_{2}^{\text {tot }}\right\rangle_{d}$, and similar for the other pollutants.

From Figures 7-9, one can estimate the reduction in percentages caused by the implementation of a green wave, although these estimates are strictly speaking only valid for a distance of $200 \mathrm{~m}$ between traffic signals. It is found that reductions vary between $10 \%$ for low traffic flows and high green split, and $40 \%$ for traffic flows near capacity and low green split, which is in accordance with the ranges reported in literature (see Section 2).

\section{Discussion}

The simulation results presented in Section 4 consider the extreme cases of the perfect green wave, in which all vehicles are able to traverse the simulated road segment without having to stop, and the perfect red wave, in which all vehicles have to stop at all traffic lights, together with the situation without signal coordination. As such, this study focused on the limits of what can be expected by introducing signal coordination. However, in practice, introducing signal coordination will almost never result in a perfect green wave, and a wide range of literature exists that investigates the conditions for which coordinated signals are effective in creating a green wave (see the references in Section 1). Examples of important factors to consider, and which could lead to the green wave (partly) breaking down, are the amount of congestion, the amount of traffic entering from sidestreets, the distance between signalized intersections, the presence of slow or heavy vehicles (i.e. a distribution of target speeds), the presence of pedestrian crossings or the effect of prioritization of public transport. Some (theoretical) studies even suggest that signal coordination has little effect when traffic is saturated, and as a consequence, a green wave can not be created for saturated traffic (Huang and Huang, 2003). Note that the green wave scheme in this study corresponds to the desynchronized scheme with $\alpha=1$ (i.e. the traffic light is always green). For non-optimal green waves, one could define the effective green split $\tilde{\alpha}<1$, accounting for a certain fraction of the traffic that has to stop at each signal. Because $\tilde{\alpha}$ can be measured easily, the results of this study could still be applied in this case.

Up to now, the influence of signal coordination on the emissions produced by reverse-flow traffic has been neglected. It can be assumed that signal coordination will only be installed when traffic flow is dominant in a single direction, such that effects caused by reverse-flow traffic can be neglected in first order. Nevertheless, the regression analysis results in this paper can be used to provide a rough estimate for the worst case scenario, in which the traffic flows in both directions are the same $\left(Q_{1}=Q_{2}=Q\right.$ and $\left.\alpha_{1}=\alpha_{2}=0.5\right)$, and where the implementation of a green wave signal coordination scheme in one direction results in the occurrence of a red wave in the opposite direction. For example, before implementing signal coordination, the total $\mathrm{CO}_{2}$ emission (for the section of interest) equals $2 \cdot Q \cdot\left\langle\mathrm{CO}_{2}^{\text {tot }}\right\rangle_{d}(\alpha, Q)$. After implementing signal coordination, the total emission would equal $Q \cdot\left[\left\langle\mathrm{CO}_{2}^{\text {tot }}\right\rangle_{g}(\alpha, Q)+\left\langle\mathrm{CO}_{2}^{\text {tot }}\right\rangle_{r}(\alpha, Q)\right]$. When the regression equations of Section 4.3 are filled in, it is found that, for low traffic flows $\left(<200\right.$ vehicles/h), the reduction in $\mathrm{CO}_{2}$ emissions due to the green wave is compensated almost completely by the increased emissions caused by the reverse-flow traffic, if the latter experiences a red wave. For higher traffic flows, the influence of reverse-flow traffic becomes smaller, e.g. a reduction of the beneficial effect by $50 \%$ for flows of 400 vehicles $/ \mathrm{h}$, to about $10 \%$ for flows of 800 vehicles $/ \mathrm{h}$. Similar results can be found for $\mathrm{NO}_{\mathrm{x}}$ and $\mathrm{PM}_{10}$ emissions. It can thus be concluded that, in case the traffic flow is low and the flow in the reverse direction is not negligible, one should aim to implement the signal coordination scheme in such a way that no red wave is experienced in the reverse direction. For higher traffic flows, possible effects on the emission of reverse-flow traffic can be neglected.

Traffic signal coordination decreases travel times and increases road capacity; the effect of facilitating traffic flow may in the long term induce additional traffic (Hills, 1996; Kitamura, 2009). This side effect potentially offsets the beneficial environmental consequences of signal coordination, or even make the situation worse (Stathopoulos and Noland, 2003). Predicting the amount of induced traffic is not a trivial task, because it depends on a wide number of intricately interrelated factors such as land use, accessibility or household's decisions concerning residence and job location (Kitamura, 2009). On the 
other hand, the results in this paper allow, to some extent, to estimate the influence of induced traffic on emissions. For example, one can easily calculate the factor $f$ by which the traffic flow $Q$ may increase in order to compensate for the effect of lowered $\mathrm{CO}_{2}$ emissions per trip, caused by the implementation of a green wave; this will be the case when

$$
Q \cdot\left\langle\mathrm{CO}_{2}^{\text {tot }}\right\rangle_{d}(\alpha, Q)=f Q \cdot\left\langle\mathrm{CO}_{2}^{\text {tot }}\right\rangle_{g}(\alpha, f Q) .
$$

Given that we found $\left\langle\mathrm{CO}_{2}^{\text {tot }}\right\rangle_{\mathrm{g}}$ to be $40.2 \mathrm{~g}$, independent of $Q$ or $\alpha$, one finds that

$$
f=1-\frac{\Delta\left\langle\mathrm{CO}_{2}^{t o t}\right\rangle(\alpha, Q)}{40.2} .
$$

Allowed increases range from $20 \%$ for low initial traffic flows and high green split, to more than $100 \%$ for high initial traffic flows and low green split (i.e. the cases for which a green wave would be most favorable). Similar ranges can be found for $\mathrm{NO}_{\mathrm{x}}$ and $\mathrm{PM}_{10}$ emissions. Potential increases in traffic flow are however closely linked to the environmental capacity of the road (Appleyard et al., 1981). The above analysis only considers the effects of increased traffic on emissions; in practice, such high increases in traffic flow may not be desired.

\section{Conclusions}

This paper reported on a study in which the influence of traffic signal coordination on vehicle noise and air pollutant emissions $\left(\mathrm{CO}_{2}, \mathrm{NO}_{\mathrm{x}}\right.$ and $\left.\mathrm{PM}_{10}\right)$ was investigated. A microscopic traffic simulation model was used, coupled with the recently developed Imagine and VERSIT+ emission models, which return results representative for the Dutch vehicle fleet. A simplified setting was considered, consisting of an urban arterial road with a limit speed of $50 \mathrm{~km} / \mathrm{h}$, and equiped with five consecutive traffic signals, spaced at a distance of $200 \mathrm{~m}$ from each other. Through the simulation of a range of scenarios, the influence of the traffic intensity, the signal coordination scheme and signal parameters (cycle time and green split) on emissions was investigated. In first order, the effects of cross-flow and reverse-flow traffic were not considered.

It was found that, for the considered setting, the introduction of a green wave could potentially lower the emissions of the considered air pollutants by $10 \%$ to at most $40 \%$ (if a perfect green wave is achieved), a range which is in accordance with those reported in literature. The traffic intensity and the green split were found to have the largest influence on the effective reduction in emission; the largest potential reduction occurs when traffic intensities are close to capacity and the green split is low. The cycle time was found to have a statistically significant influence only on travel times, but not on the emission of the pollutants considered. The introduction of a green wave resulted in all cases in an increase of the total emitted noise level, by up to $0.6 \mathrm{~dB}(\mathrm{~A})$. Sound pressure levels were found to decrease by up to $1 \mathrm{~dB}(\mathrm{~A})$ near the traffic signals, but to increase by up to $1.5 \mathrm{~dB}(\mathrm{~A})$ between intersections. Often, efficient coordination of traffic signals is only possible in one travelling direction, and the potential effects of this measure on traffic driving in the reverse direction are also of concern. A more detailed analysis in this work showed that installing a green wave slightly increased road capacity, but that having no signal coordination already represented the worst case regarding road capacity. This implies that implementing signal coordination in one direction will not have an adverse effect on road capacity in the opposite direction. Furthermore, for higher traffic flows ( $>200$ vehicles $/ \mathrm{h}$ ), possible effects of installing a green wave on the emission of reverse-flow traffic can also be neglected. Although applied to the specific case of traffic signal coordination, the methodology presented in this paper could be used to study the effects of a wide range of intelligent transportation systems.

\section{Acknowledgments}

This study was performed within the framework of the Center for Mobility and Public Works (Steunpunt Mobiliteit \& Openbare Werken, Spoor Verkeersveiligheid), which is supported by the Flemish Government. Bert De Coensel is a postdoctoral fellow of the Research Foundation-Flanders (FWOVlaanderen); the support of this organization is also gratefully acknowledged.

\section{References}

Ahn, K., Rakha, H., Trani, A., Van Aerde, M., 2002. Estimating vehicle fuel consumption and emissions based on instantaneous speed and acceleration levels. J. Transp. Engrg. 128, 182-190.

Appleyard, D., Gerson, M.S., Lintell, M., 1981. Livable streets. University of California Press, Berkeley, California, USA.

Barkenbus, J.N., 2010. Eco-driving: an overlooked climate change initiative. Energy Policy 38, 762-769.

Bérengier, M.C., 2009. Emission, propagation and control of road traffic noise: some solutions for the future, in: Proc. Inter-noise, Ottawa, Canada.

Bérengier, M.C., Picaut, J., 2008. Methods for noise control by traffic management: Impact of speed reducing equipments. Deliverable H.R2. SILENCE Project, Sixth Framework Programme, European Commission. Brussels, Belgium.

Botteldooren, D., De Coensel, B., De Muer, T., 2006. The temporal structure of urban soundscapes. J. Sound Vib. 292, 105-123.

Bretherton, D., Bodger, M., Baber, N., 2004. SCOOT — the future [urban traffic control], in: Proceedings of the 12th International Conference on Road Transport Information and Control (RTIC), London, UK. pp. 301-306.

Brockfeld, E., Barlovic, R., Schadschneider, A., Schreckenberg, M., 2001. Optimizing traffic lights in a cellular automaton model for city traffic. Phys. Rev. E 64, 056132.

Cameron, G.D.B., Duncan, G.I.D., 1996. PARAMICS—parallel microscopic simulation of road traffic. J. Supercomput. 10, 25-53.

Can, A., Leclercq, L., Lelong, J., 2008. Dynamic estimation of urban traffic noise: influence of traffic and noise source representations. Appl. Acoust. 69, 858-867.

Can, A., Leclercq, L., Lelong, J., Defrance, J., 2009. Accounting for traffic dynamics improves noise assessment: Experimental evidence. Appl. Acoust. $70,821-829$.

Chen, K., Yu, L., 2007. Microscopic traffic-emission simulation and case study for evaluation of traffic control strategies. J. Transpn. Sys. Eng. \& IT 7, 93-100.

Cheng, S.F., Epelman, M.A., Smith, R.L., 2006. CoSIGN: A parallel algorithm for coordinated traffic signal control. IEEE Trans. Intell. Transp. Syst. 7, 551-564.

Chowdhury, D., Schadschneider, A., 1999. Self-organisation of traffic jams in cities: Effects of stochastic dynamics and signal periods. Phys. Rev. E 59, R1311-R1314. 
Coelho, M.C., Farias, T.L., Rouphail, N.M., 2005a. Impact of speed control traffic signals on pollutant emissions. Transport. Res. D 10, 323-340.

Coelho, M.C., Farias, T.L., Rouphail, N.M., 2005b. A methodology for modelling and measuring traffic and emission performance of speed control traffic signals. Atmos. Environ. 39, 2367-2376.

David, G., 2000. Caractérisation physique des sources sonores en milieu urbain (Physical characterization of sound sources in urban environment). Ph.D. thesis. University of Maine. France.

De Coensel, B., Botteldooren, D., De Muer, T., Berglund, B., Nilsson, M.E., Lercher, P., 2009. A model for the perception of environmental sound based on notice-events. J. Acoust. Soc. Am. 126, 656-665.

De Coensel, B., Botteldooren, D., Vanhove, F., Logghe, S., 2007. Microsimulation based corrections on the road traffic noise emission near intersections. Acta Acust. Acust. 93, 241-252.

De Coensel, B., De Muer, T., Yperman, I., Botteldooren, D., 2005. The influence of traffic flow dynamics on urban soundscapes. Appl. Acoust. 66, 175-194.

Della Ragione, L., Meccariello, G., Punzo, V., Ciuffo, B., 2009. A preliminary study to evaluate emissions factors by real and micro simulated driving cycle, in: Proceedings of the 9th International Conference on Engines and Vehicles, Naples, Italy.

Desarnaulds, V., Monay, G., Carvalho, A., 2004. Noise reduction by urban traffic management, in: Proc. ICA, Kyoto, Japan.

Ellebjerg, L., 2007. Effectiveness and benefits of traffic flow measures on noise control. Deliverable H.D1. SILENCE Project, Sixth Framework Programme, European Commission. Brussels, Belgium.

Ellenberg, M., Bedeaux, J.F., 1999. Calming waves for safety: A time to rethink green waves? Traffic Technol. Int. April/May, 55-58.

European Commission, 2007. Towards a new culture for urban mobility. Green Paper 551. Directorate General for Energy and Transport, European Commission. Brussels, Belgium.

European Commission, 2008. Action plan for the deployment of intelligent transport systems in Europe. Communication from the Commission 886 European Commission. Brussels, Belgium.

Fritzsche, H.T., 1994. A model for traffic simulation. Traffic Eng. Contr. 35, 317-321.

Gartner, N.H., Stamatiadis, C., 2002. Arterial-based control of traffic flow in urban grid networks. Math. Comput. Model. 35, 657-671.

Helbing, D., 2001. Traffic and related self-driven many-particle systems. Rev. Mod. Phys. 73, 1067-1141.

Hills, P.J., 1996. What is induced traffic? Transportation 23, 5-16.

Huang, D.W., Huang, W.N., 2003. Traffic signal synchronization. Phys. Rev. E 67, 056124

Int Panis, L., Broekx, S., Liu, R., 2006. Modelling instantaneous traffic emission and the influence of traffic speed limits. Sci. Total Environ. 371, 270 285

Kitamura, R., 2009. The effects of added transportation capacity on travel: a review of theoretical and empirical results. Transportation 36, 745-762.

Knospe, W., Santen, L., Schadschneider, A., Schreckenberg, M., 2002. Human behavior as origin of traffic phases. Phys. Rev. E 65.

Li, X., Li, G., Pang, S.S., Yang, X., Tian, J., 2004. Signal timing of intersections using integrated optimization of traffic quality, emissions and fuel consumption: a note. Transport. Res. D 9, 401-407.

Ligterink, N.E., De Lange, R., 2009. Refined vehicle and driving-behaviour dependencies in the VERSIT+ emission model, in: Proceedings of the Joint 17th Transport and Air Pollution Symposium and 3rd Environment and Transport Symposium (ETTAP), Toulouse, France.

Lum, K.M., Fan, H.S.L., Lam, S.H., Olszewski, P., 1998. Speed-flow modeling of arterial roads in Singapore. J. Transp. Engrg. 124, 213-222.

Madireddy, M., De Coensel, B., Can, A., Degraeuwe, B., Beusen, B. De Vlieger, I., Botteldooren, D., 2011. Assessment of the impact of speed limit reduction and traffic signal coordination on vehicle emissions using an integrated approach. Transport. Res. D 16, 504-508.

Mensink, C., Cosemans, G., 2008. From traffic flow simulations to pollutant concentrations in street canyons and backyards. Environ. Modell. Softw. 23, 288-295.

Nagatani, T., 2007. Vehicular traffic through a sequence of green-wave lights. Physica A 380, 503-511.

Nagatani, T., 2009. Green-light paths in city traffic controlled by signals. Phys. Lett. A 373, 536-539.

Neunhäuserer, L., Diegmann, V., 2010. Analysis of the impacts of an environ- mental traffic management system on vehicle emissions and air quality, in: Proceedings of the 18th International Symposium Transport and Air Pollution (TAP'10), Dübendorf, Switzerland.

Osorio, C., Bierlaire, M., 2008. A multiple model approach for traffic signal optimization in the city of Lausanne, in: Proceedings of the 8th Swiss Transport Research Conference (STRC), Monte Verità, Ascona, Switzerland.

Pandian, S., Gokhale, S., Ghoshal, A.K., 2009. Evaluating effects of traffic and vehicle characteristics on vehicular emissions near traffic intersections. Transport. Res. D 14, 180-196.

Peeters, B., van Blokland, G., 2007. The noise emission model for European road traffic. Technical Report - Deliverable 11 of the Imagine project IMA55TR-060821-MP10. M+P Consulting Engineers. Vught, The Netherlands.

Rakha, H., Van Aerde, M., Ahn, K., Trani, A.A., 2000. Requirements for evaluating traffic signal control impacts on energy and emissions based on instantaneous speed and acceleration measurements, in: Proceedings of the 79th Annual Meeting of the Transportation Research Board, Washington D.C., USA.

Shinar, D., Bourla, M., Kaufman, L., 2004. Synchronization of traffic signals as a means of reducing red-light running. Hum. Factors 46, 367-372.

Silva, C.M., Farias, T.L., Frey, H.C., Rouphail, N.M., 2006. Evaluation of numerical models for simulation of real-world hot-stabilized fuel consumption and emissions of gasoline light-duty vehicles. Transport. Res. D 11, 377385.

Smit, R., Brown, A.L., Chan, Y.C., 2008. Do air pollution emissions and fuel consumption models for roadways include the effects of congestion in the roadway traffic flow? Environ. Modell. Softw. 23, 1262-1270.

Smit, R., McBroom, J., 2009. Use of microscopic simulation models to predict traffic emissions. Road Transp. Res. 18, 49-54.

Smit, R., Smokers, R., Rabé, E., 2007. A new modelling approach for road traffic emissions: VERSIT+. Transport. Res. D 12, 414-422.

Smit, R., Smokers, R., Schoen, E., 2005. VERSIT+LD: Development of a new emission factor model for passenger cars linking real-world emissions to driving cycle characteristics, in: Proceedings of the 14th International Symposium Transport and Air Pollution (TAP'05), Graz, Austria. pp. 177186

Stathopoulos, F.G., Noland, R.B., 2003. Induced travel and emissions from traffic flow improvement projects, in: Proceedings of the 82nd Annual Meeting of the Transportation Research Board, Washington D.C., USA.

Tindale, S.A., Hsu, P.P., 2005. Crash data and signal coordination: A one-way pair case study. J. Saf. Res. 36, 481-482.

Unal, A., Rouphail, N.M., Frey, H.C., 2003. Effect of arterial signalization and level of service on measured vehicle emissions, in: Proceedings of the 82nd Annual Meeting of the Transportation Research Board, Washington D.C., USA.

Varas, A., Cornejo, M.D., Toledo, B.A., Muñoz, V., Rogan, J., Zarama, R., Valdivia, J.A., 2009. Resonance, criticality, and emergence in city traffic investigated in cellular automaton models. Phys. Rev. E 80, 056108.

Warberg, A., Larsen, J., Jørgensen, R.M., 2008. Green Wave Traffic Optimization - A Survey. Technical Report. Department of Informatics and Mathematical Modelling, Technical University of Denmark. Lyngby, Denmark.

Webster, F.V., 1958. Traffic signal setting. Road Research Technical Paper 39. Her Majesty's Stationery Office. London, UK.

Zallinger, M., Luz, R., Hausberger, S., Hirschmann, K., Fellendorf, M., 2010. Coupling of microscale traffic and emission models to minimize emissions by traffic control systems, in: Proceedings of the 18th International Symposium Transport and Air Pollution (TAP'10), Dübendorf, Switzerland.

Zhang, Y., Chen, X., Zhang, X., Song, G., Hao, Y., Yu, L., 2009. Assessing effect of traffic signal control strategies on vehicle emissions. J. Transpn. Sys. Eng. \& IT 9, 150-155.

Zito, P., 2009. Influence of coordinated traffic lights parameters on roadside pollutant concentrations. Transport. Res. D 14, 604-609. 